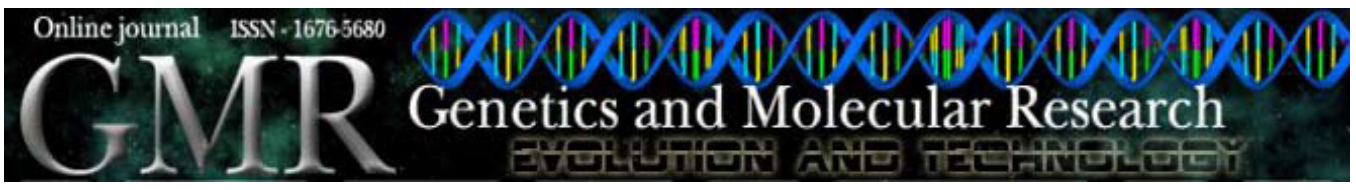

\title{
Lack of association of C282Y and H63D mutations in the hemochromatosis (HFE) gene with diabetes mellitus type 2 in a case-control study of women in Brazil
}

K.B. Gomes ${ }^{1,2}$, M.G. Carvalho ${ }^{1}$, F.F. Coelho ${ }^{1}$, I.F. Rodrigues ${ }^{2}$, A.L. Soares ${ }^{1}$ D.A. Guimarães ${ }^{1}$ and A.P. Fernandes ${ }^{1}$

${ }^{1}$ Faculdade de Farmácia, Universidade Federal de Minas Gerais, Belo Horizonte, MG, Brasil ${ }^{2}$ Colégio Técnico, Universidade Federal de Minas Gerais, Belo Horizonte, MG, Brasil

Corresponding author: K.B. Gomes

Email: karina@coltec.ufmg.br

Genet. Mol. Res. 8 (4): 1285-1291 (2009)

Received May 29, 2009

Accepted August 27, 2009

Published October 27, 2009

ABSTRACT. Hereditary hemochromatosis is one of the most common autosomal recessive diseases; it is characterized by excess absorption of iron. Clinically, the major challenge is to diagnose increased iron deposition before irreversible tissue damage has occurred. C282Y and $\mathrm{H} 63 \mathrm{D}$ are the main mutations related to hereditary hemochromatosis; these mutations have been reported to be associated with increased risk of developing diabetes mellitus type 2 (DM2). We investigated whether these mutations are associated with increased risk for the development of DM2 in women in Brazil. Seventy-two women with clinical diagnosis of DM2 under treatment with hypoglycemic agents and a control group composed of 72 women with no clinical history of diabetes were studied. The $\mathrm{C} 282 \mathrm{Y}$ and H63D mutations were determined by PCR-RFLP. Significant differences were not observed for $\mathrm{C} 282 \mathrm{Y}$ and $\mathrm{H} 63 \mathrm{D}$, when we compared diabetic and non-diabetic women. We suggest that mutations $\mathrm{C} 282 \mathrm{Y}$ and H63D in the HFE 
gene are not significant risk factors for the development of DM2 in Brazilian women.

Key words: Hereditary hemochromatosis; HFE; C282Y; H63D; Diabetes mellitus type 2; Women

\section{INTRODUCTION}

Hereditary hemochromatosis $(\mathrm{HH})$ is one of the most common autosomal recessive inherited diseases and is characterized by excess absorption of iron through the intestine (Jacobs et al., 2007). The initial symptoms are nonspecific, but in advanced stages diabetes mellitus, hypogonadism and other endocrinopathies, cardiomyopathies, cirrhosis, and even predisposition to liver cancer may be observed (Habeos et al., 2003).

Clinically, the major challenge is to diagnose increased iron deposition before the occurrence of irreversible damages in the tissues and at the same time to distinguish $\mathrm{HH}$ from other clinical alterations that may raise iron levels, such as metabolic syndrome. Early diagnosis and therapeutic phlebotomy can prevent the development of tissue damage, increasing the survival of the patients. However, some symptoms persist after therapy has been introduced, such as arthropathies (Janssen, 2007).

A predominance of the disease in males, with a ratio of 3:1 usually observed, may be explained because women benefit from the protective effect of menstruation, events in which the plasma concentration of iron is reduced periodically through physiological loss of blood, and pregnancy, regard to tissue growth demands (Pietrangelo, 2004; Scotet et al., 2005).

The development of $\mathrm{HH}$ is more frequently related to the HFE gene, located in the short arm of chromosome 6. This gene codes for the HFE protein, which is located on the cell surface of duodenal crypts where it is associated with b2-microglobulin and transferrin. The presence of mutations in this gene decreases the connection of the protein to the transferrin receptor by modifying the conformation of the HFE protein, leading to a lesser capture of iron by transferrin and greater absorption and deposit of iron in the body (Bittencourt et al., 2002). C282Y is the main mutation related to $\mathrm{HH}$, present in $83 \%$ of patients who show the genotype YY (mutation in homozygosity), although its prevalence significantly varies in different ethnic groups (Beutler et al., 1996; Carella et al., 1997; Anonymous, 1997; Pietrangelo et al., 1999; Camaschella et al., 2000; Jacobs et al., 2007). This mutation consists of the substitution of a guanine (G) by an adenine (A) at nucleotide 845 , which leads to an exchange of the amino acid cysteine (C) by tyrosine (Y) at position 282.

The second variant, H63D, consists of the substitution of a cytosine (C) by a guanine $(\mathrm{G})$ at nucleotide 187 , which results in the exchange of histidine $(\mathrm{H})$ by aspartic acid (D) at position 63 ; it seems to act synergistically with the $\mathrm{C} 282 \mathrm{Y}$ mutation, since there is a linkage disequilibrium between the two mutations (Feder et al., 1996; Halsall et al., 2003). Few studies have been carried out in Brazil to determine the frequency of these mutations in individuals with clinical suspicion of HH. Ferreira et al. (2008), evaluating 1955 Brazilian individuals with clinical suspicion of $\mathrm{HH}$, observed that the $\mathrm{C} 282 \mathrm{Y}$ mutation was present in homozygosity in only $2.9 \%$ and in heterozygosity in $10.1 \%$ of the subjects. The H63D mutation was found in $4.3 \%$ of the patients in homozygosity and 
$30.6 \%$ in heterozygosity. Combined heterozygous (C282Y/H63D) was observed in 3\% of the patients. However, among these patients there were also other risk factors that could better explain the suspicious symptoms such as alcoholism, viruses and other hepatic diseases. Moreover, individuals from the same family and carriers of these mutations displayed different $\mathrm{HH}$ clinical manifestations. Altogether, these data suggest that these mutations show low penetrance in the studied population (Janssen, 2007).

A particular group of patients with HH consists of individuals who are heterozygotes for both $\mathrm{C} 282 \mathrm{Y}$ and $\mathrm{H} 63 \mathrm{D}$ mutations. These individuals have an increased risk for excess iron absorption, but in a less severe form compared to those homozygous for C282Y (Janssen, 2007).

Diabetes mellitus type 2 (DM2) develops in about 20 to $50 \%$ of the patients with $\mathrm{HH}$ (Niederau et al., 1985; Adams et al., 1991; Fargion et al., 1992; Moczulski et al., 2001), and the presence of the $\mathrm{C} 282 \mathrm{Y}$ mutation in the heterozygous form seems to be associated with increased risk for developing DM (Nelson et al., 1995). Although the penetrance of these mutations is low and even though the importance of the isolated H63D mutation on the development of HH is still controversial, it is known that the presence of these alterations may negatively influence insulin synthesis and secretion due to the accumulation of iron in the pancreas, an event that can precede the clinical manifestations of the HH (Niederau et al., 1984; Felber et al., 1987; Merkel et al., 1988; Hramiak et al., 1997; Jacobs et al., 2007).

Kwan et al. (1998) observed an increase in the C282Y mutation frequency in patients with DM2. Moczulski et al. (2001) confirmed the previous data and also observed that diabetics carrying the H63D mutation had a greater possibility to develop diabetic nephropathy. However, Fernandes-Real et al. (1999) observed an increased frequency only for the H63D mutation in diabetic patients when compared to the control group, while other studies did not find any association between the presence of the two mutations and the development of diabetes (Braun et al., 1998; Dubois-Laforgue, 1998; Frayling et al., 1998; Florkowski et al., 1999; Halsall et al., 2003; Genuth et al., 2003).

Therefore, the studies that have evaluated the association between the $\mathrm{C} 282 \mathrm{Y}$ and H63D mutations in the HFE gene and diabetes are not conclusive. The present study aimed to investigate whether these mutations are associated with increased risk for the development of DM2 in women in Brazil, since no previous studies have been conducted to date in an attempt to resolve this question in the Brazilian population.

\section{MATERIAL AND METHODS}

\section{Individuals}

In this study, 72 women were evaluated; they had an average age of $57.1 \pm 8.3$ years. All the participants of this group showed blood glucose levels equal to or greater than 126 $\mathrm{mg} / \mathrm{dL}$, with clinical diagnosis of DM2 and were under treatment with hypoglycemic agents. Women with DM2 caused by medicines, anemia, chronic kidney failure or inflammatory diseases, and smokers and alcohol users were excluded from this study (Oberley, 1988).

As part of this study, a control group composed of 72 women with an average age of $53.6 \pm 6.7$ years and with no clinical history of diabetes was also studied. This study was approved by the Committee of Ethics in Research of the Federal University of Minas Gerais (COEP-UFMG). All participants signed an informed consent form to participate in this study. 


\section{Molecular analysis}

Peripheral blood was collected in EDTA using the Vacuette system ${ }^{\circledR}$ (Geiner BioOne). DNA was extracted using the Wizard Genomic DNA Purificaton $\mathrm{Kit}^{\circledR}$ (Promega).

The $\mathrm{C} 282 \mathrm{Y}$ mutation was detected with the following oligonucleotides: forward 5'TGGCAAGGGTAAACAGATCC3', reverse - 5'CTCAGGCACTCCTCTCAACC-3'. The H63D mutation was detected with the following sequences: sense 5'ACATGGTTAAGGCCTGTTGC3', anti-sense-5'GCCACATCTGGCTTGAAATT3'. Segments of the HFE gene were amplified separately by polymerase chain reaction (PCR), in a final volume of $20 \mu \mathrm{L}$ containing: $0.5 \mu \mathrm{L}$ DNA, $0.8 \mu \mathrm{L}$ of each primer $(10$ $\mathrm{pmol} / \mu \mathrm{L}$ ), $0.25 \mu \mathrm{L}$ Taq DNA polymerase (Phoneutria ${ }^{\circledR}$ ), $1.5 \mu \mathrm{L}$ dNTPs (Invitrogen ${ }^{\circledR}$ ) and $2.0 \mu \mathrm{L} \mathrm{10X}$ buffer $\left(\right.$ Phoneutria $\left.{ }^{\circledR}\right)$. After an initial denaturation at $96^{\circ} \mathrm{C}$ for $2 \mathrm{~min}$, the amplification was carried out in 40 cycles: denaturation at $96^{\circ} \mathrm{C}$ for $30 \mathrm{~s}$, annealing at $56^{\circ} \mathrm{C}$ for $1 \mathrm{~min}$, and extension at $72^{\circ} \mathrm{C}$ for $1 \mathrm{~min}$, followed by a final extension for $10 \mathrm{~min}$ at $72^{\circ} \mathrm{C}$.

The PCR products were submitted to enzymatic digestion with $1 \mathrm{U}$ restriction enzymes $R s a \mathrm{I}$ and $B c l \mathrm{I}$ for detection of the $\mathrm{C} 282 \mathrm{Y}$ and H63D mutations, respectively. In the absence of the C282Y mutation, RsaI cleaves PCR products into fragments of 247 and $140 \mathrm{bp}$, while the presence of this mutation in homozygosity results in fragments of 247, 111, and $29 \mathrm{bp}$. For the H63D mutation, the presence of this mutation in the homozygous form results in only one fragment of $208 \mathrm{bp}$, whereas in the absence of the mutation fragments of 138 and $70 \mathrm{bp}$ are produced. The fragments were visualized on a $6 \%$ polyacrylamide gel, stained with silver nitrate.

\section{Statistical analysis}

The association between the presence of the C282Y and H63D mutations and DM2 was evaluated using the Fisher test or the chi-square test, using the Stat Sigma version 1.0 and Genepop softwares (http://genepop.curtin.edu.au/) (Rousset and Raymond, 1995). Significant differences were considered for values of $\mathrm{P}<0.05$.

\section{RESULTS}

The allele frequencies detected for the $\mathrm{C} 282 \mathrm{Y}$ and $\mathrm{H} 63 \mathrm{D}$ mutations followed the HardyWeinberg equilibrium in the patient and control groups $(\mathrm{P}=1$ for $\mathrm{C} 282 \mathrm{Y} ; \mathrm{P}=0.57$ for $\mathrm{H63D})$.

For C282Y, the frequency of the wild allele (C) was 0.979 in the patient group and 0.986 in the control group. For the mutant allele (Y), the frequency was 0.021 in the patient group and 0.014 in the control group. The wild allele $(\mathrm{H})$ for the H63D mutation showed in the patient and control groups frequencies of 0.889 and 0.882 , respectively, while the frequencies of the mutant allele (D) were 0.111 and 0.118 for the same groups studied.

With regard to genotype frequency, three patients had the C282Y mutation in the heterozygous form while 14 had the H63D mutation in heterozygosity and only one had this mutation in homozygosity. These frequencies were similar to the ones found in the control group, since two women had the $\mathrm{C} 282 \mathrm{Y}$ mutation in the heterozygous form, 13 had the H63D mutation in heterozygosity and 2 in homozygosity. None of the participants were double heterozygous (CY/HD) (Table 1). 


\begin{tabular}{|c|c|c|c|c|}
\hline Mutation/genotype & Diabetic & Non-diabetic & $P$ & OR $(95 \% \mathrm{CI})$ \\
\hline \multicolumn{5}{|l|}{$\mathrm{C} 282 \mathrm{Y}$} \\
\hline $\mathrm{CC}$ & $69(96 \%)$ & $70(97 \%)$ & & \\
\hline CY & $3(4.0 \%)$ & $2(3.0 \%)$ & 1 & 0.657 \\
\hline YY & 0 & 0 & & \\
\hline \multicolumn{5}{|l|}{$\mathrm{H} 63 \mathrm{D}$} \\
\hline $\mathrm{HH}$ & $57(79 \%)$ & $57(79 \%)$ & & \\
\hline HD & $14(20 \%)$ & $13(18 \%)$ & 1 & 1 \\
\hline DD & $1(1.0 \%)$ & $2(3.0 \%)$ & & \\
\hline
\end{tabular}

Data are reported as number with percent in parentheses for a total of 72 women in each group. $\mathrm{OR}=$ odds ratio for the model CC vs CY and YY or HH vs HD and DD. $95 \% \mathrm{CI}=$ confidence interval at $95 \%$.

Comparing the mutation frequencies between the groups studied, significant differences were not observed, either for $\mathrm{C} 282 \mathrm{Y}(\mathrm{P}=1 ; \mathrm{OR}=0.657 ; \mathrm{CI}=0.127-3.406)$ or $\mathrm{H} 63 \mathrm{D}(\mathrm{P}$ $=1 ; \mathrm{OR}=1 ; \mathrm{CI}=0.452-2.211$ ) between diabetic and non-diabetic women.

\section{DISCUSSION}

It has been hypothesized that iron accumulation due to HFE mutations could be associated with the development of DM2 (Kwan et al., 1998; Fernandez-Real et al., 1999; Moczulski et al., 2001). Beyond directly affecting the release of insulin in the pancreas, iron overload can increase the oxidation of free fatty acids, which diminishes glucose use in muscles and increases gluconeogenesis in the liver, leading to insulin resistance (Felber et al., 1987; Anonymous, 2006). A study conducted by Niederau et al. (1984) in patients with non-cirrhotic diagnosis of $\mathrm{HH}$ demonstrated that the accumulation of iron in the body leads to the development of insulin resistance. Considering that resistance to insulin is a common finding in DM2, we decided to investigate whether the frequency of the two mutations is increased in patients with no suspicion of $\mathrm{HH}$, but previously diagnosed with DM2. In other words, our main interest was to search a possible direct association between the presence of such mutations and DM2 rather than mutations favoring $\mathrm{HH}$ and consequently DM2.

To test this hypothesis in individuals of the Brazilian population, women diagnosed with DM2 were selected, and the frequency of the C282Y and H63D mutations in the HFE gene in this group was compared with a control group composed of women without the disease. It is known that clinical manifestation of $\mathrm{HH}$ varies according to gender (Pietrangelo, 2004; Scotet et al., 2005). Therefore, only women were selected to compose the groups studied. Moreover, due to the fact that expression of $\mathrm{HH}$ is frequently delayed in females as a consequence of physiological blood loss during menstruation, only women older than 40 years were included in our study, where the majority of them were in the menopause period, when the accumulation of iron becomes more evident as a consequence of HFE gene mutations. It is noteworthy that the inclusion criterium in the control group was defined on the basis of individual self-report of the absence of DM2 diagnosis, as in the protocol described by Sampson et al. (2000). Biochemical data were not used as exclusion criteria in this group, so the presence of DM2 might have been under-estimated. 
The homozygous frequencies for the $\mathrm{C} 282 \mathrm{Y}$ mutation in both the control group and diabetic group $(0 \%)$ were smaller than the frequencies observed in Caucasian $(0.44 \%)$, Hispanic $(0.027 \%)$ and Black $(0.014 \%)$ populations (Sampson et al., 2000). For the H63D mutation, the number of homozygous and heterozygous individuals in the two groups studied (Table 1) was also smaller compared to the one reported in Brazilians with clinical suspicion of HH (Ferreira et al., 2008). No significant association could be demonstrated between the presence of the $\mathrm{C} 282 \mathrm{Y}$ and H63D mutations and the development of DM2 in Brazilian women, in contrast to the results of other studies (Nelson et al., 1995; Kwan et al., 1998). These studies, for the majority, were conducted in more genetically homogeneous populations, compared to the Brazilian population in which there has been a great deal of miscegenation and shows a lower frequency of mutations in the HFE gene. Thus, gene-disease association studies suffer important variations that depend on the population make-up.

The results obtained in the present study suggest that the C282Y and H63D mutations in the HFE gene are not significant risk factors for the development of DM2 in Brazilian women. Although these findings do not support the hypothesis that mutations in the HFE gene are relevant for DM2 development in Brazilian women, we cannot discard their possible implication in insulin deficiency, since this clinical condition was not evaluated as criteria for the diagnosis of diabetes among the participants. Nonetheless, it could be recommended that if these mutations are present, for instance in first-degree relatives of $\mathrm{HH}$ patients, a study regarding insulin deficiency should always be performed in order to evaluate the development of DM2.

\section{REFERENCES}

Adams PC, Speechley M and Kertesz AE (1991). Long-term survival analysis in hereditary hemochromatosis. Gastroenterology 101: 368-372.

Anonymous (1997). A simple genetic test identifies $90 \%$ of UK patients with haemochromatosis. The UK Haemochromatosis Consortium. Gut 41: 841-844.

Anonymous (2006). Screening for hemochromatosis: recommendation statement. Ann. Intern. Med. 145: 204-208.

Beutler E, Gelbart T, West C, Lee P, et al. (1996). Mutation analysis in hereditary hemochromatosis. Blood Cells Mol. Dis. 22: 187-194.

Bittencourt PL, Palacios SA, Couto CA, Cancado EL, et al. (2002). Analysis of HLA-A antigens and C282Y and H63D mutations of the HFE gene in Brazilian patients with hemochromatosis. Braz. J. Med. Biol. Res. 35: 329-335.

Braun J, Donner H, Plock K, Rau H, et al. (1998). Hereditary haemochromatosis mutations (HFE) in patients with type II diabetes mellitus. Diabetologia 41: 983-984.

Camaschella C, Roetto A, Cali A, De Gobbi M, et al. (2000). The gene TFR2 is mutated in a new type of haemochromatosis mapping to 7q22. Nat. Genet. 25: 14-15.

Carella M, D'Ambrosio L, Totaro A, Grifa A, et al. (1997). Mutation analysis of the HLA-H gene in Italian hemochromatosis patients. Am. J. Hum. Genet. 60: 828-832.

Dubois-Laforgue D, Caillat-Zucman S, Djilali-Saiah I, Larger E, et al. (1998). Mutations in HFE, the hemochromatosis candidate gene, in patients with NIDDM. Diabetes Care 21: 1371-1372.

Fargion S, Mandelli C, Piperno A, Cesana B, et al. (1992). Survival and prognostic factors in 212 Italian patients with genetic hemochromatosis. Hepatology 15: 655-659.

Feder JN, Gnirke A, Thomas W, Tsuchihashi Z, et al. (1996). A novel MHC class I-like gene is mutated in patients with hereditary haemochromatosis. Nat. Genet. 13: 399-408.

Felber JP, Ferrannini E, Golay A, Meyer HU, et al. (1987). Role of lipid oxidation in pathogenesis of insulin resistance of obesity and type II diabetes. Diabetes 36: 1341-1350.

Fernandez-Real JM, Vendrell J, Baiget M, Gimferrer E, et al. (1999). C282Y and H63D mutations of the hemochromatosis candidate gene in type 2 diabetes. Diabetes Care 22: 525-526.

Ferreira AS, Oliveira VC, Caxito FA, Gomes KB, et al. (2008). Prevalence of C282Y and H63D mutations in the HFE gene of Brazilian individuals with clinical suspicion of hereditary hemochromatosis. Rev. Bras. Hematol. Hemoter. 30: 379-383. 
Florkowski CM, George PM, Willis JA, Stott MK, et al. (1999). Haemochromatosis gene mutations Cys282Tyr and His63Asp are not increased in type 2 diabetic patients compared with the Canterbury (New Zealand) general population. Diabetes Res. Clin. Pract. 43: 199-203.

Frayling T, Ellard S, Grove J, Walker M, et al. (1998). C282Y mutation in HFE (haemochromatosis) gene and type 2 diabetes. Lancet 351: 1933-1934.

Genuth S, Alberti KG, Bennett P, Buse J, et al. (2003). Follow-up report on the diagnosis of diabetes mellitus. Diabetes Care 26: 3160-3167.

Habeos IG, Psyrogiannis A, Kyriazopoulou V, Psilopanagiotou A, et al. (2003). The role of hemochromatosis C282Y and H63D mutations in the development of type 2 diabetes mellitus in Greece. Hormones 2: 55-60.

Halsall DJ, McFarlane I, Luan J, Cox TM, et al. (2003). Typical type 2 diabetes mellitus and HFE gene mutations: a population-based case - control study. Hum. Mol. Genet. 12: 1361-1365.

Hramiak IM, Finegood DT and Adams PC (1997). Factors affecting glucose tolerance in hereditary hemochromatosis. Clin. Invest. Med. 20: 110-118.

Jacobs EM, Hendriks JC, Marx JJ, van Deursen CT, et al. (2007). Morbidity and mortality in first-degree relatives of C282Y homozygous probands with clinically detected haemochromatosis compared with the general population: the HEmochromatosis FAmily Study (HEFAS). Neth. J. Med. 65: 425-433.

Janssen MC (2007). Hereditary haemochromatosis. Neth. J. Med. 65: 409-410.

Kwan T, Leber B, Ahuja S, Carter R, et al. (1998). Patients with type 2 diabetes have a high frequency of the C282Y mutation of the hemochromatosis gene. Clin. Invest. Med. 21: 251-257.

Merkel PA, Simonson DC, Amiel SA, Plewe G, et al. (1988). Insulin resistance and hyperinsulinemia in patients with thalassemia major treated by hypertransfusion. N. Engl. J. Med. 318: 809-814.

Moczulski DK, Grzeszczak W and Gawlik B (2001). Role of hemochromatosis C282Y and H63D mutations in HFE gene in development of type 2 diabetes and diabetic nephropathy. Diabetes Care 24: 1187-1191.

Nelson RL, Davis FG, Persky V and Becker E (1995). Risk of neoplastic and other diseases among people with heterozygosity for hereditary hemochromatosis. Cancer 76: 875-879.

Niederau C, Berger M, Stremmel W, Starke A, et al. (1984). Hyperinsulinaemia in non-cirrhotic haemochromatosis: impaired hepatic insulin degradation? Diabetologia 26: 441-444.

Niederau C, Fischer R, Sonnenberg A, Stremmel W, et al. (1985). Survival and causes of death in cirrhotic and in noncirrhotic patients with primary hemochromatosis. N. Engl. J. Med. 313: 1256-1262.

Oberley LW (1988). Free radicals and diabetes. Free Radic. Biol. Med. 5: 113-124.

Pietrangelo A (2004). Hereditary hemochromatosis - a new look at an old disease. N. Engl. J. Med. 350: 2383-2397.

Pietrangelo A, Montosi G, Totaro A, Garuti C, et al. (1999). Hereditary hemochromatosis in adults without pathogenic mutations in the hemochromatosis gene. N. Engl. J. Med. 341: 725-732.

Rousset F and Raymond M (1995). Testing heterozygote excess and deficiency. Genetics 140: 1413-1419.

Sampson MJ, Williams T, Heyburn PJ, Greenwood RH, et al. (2000). Prevalence of HFE (hemochromatosis gene) mutations in unselected male patients with type 2 diabetes. J. Lab. Clin. Med. 135: 170-173.

Scotet V, Le Gac G, Merour MC, Mercier AY, et al. (2005). Impact of HFE genetic testing on clinical presentation of hereditary hemochromatosis: new epidemiological data. BMC Med. Genet. 6: 24. 